\title{
Gamifying Content and Language Integrated Learning with Serious Videogames
}

\begin{abstract}
Ricardo Casañ Pitarch
Universitat Jaume I

Correspondence concerning this article should be addressed to Ricardo Casañ Pitarch, Universitat Jaume I, Av. de Vicent Sos Baynat, s/n 12071 Castelló de la Plana Spain. E-mail: casanr@uji.es

New methods and approaches focusing on foreign language teaching are continuously being developed and applied in the classroom at different educational levels. The interest in raising learners' competences in foreign languages has been a fact in the last few decades. In this sense, approaches integrating the learning of non-linguistic content through a vehicular language that is not the learners' mother tongue have been widely used around the world. However, it seems that some benefits of those approaches integrating language and content could be further strengthened if the time of exposure to content and language was higher and if students were highly motivated to learn. To this purpose, this article suggests that serious videogames could be a suitable tool to provide learners with further teaching support and increase their motivation in a playful context and introduces a model that aims at gamifying and integrating content and language learning through serious videogames.
\end{abstract}

Keywords: videogames, CLIL, gamification, education, language learning

Methods and approaches for language teaching are constantly changing; one of the tendencies for language learning in the first two decades of the 21 st century concerns the instrumental use of the target language to teach contents. The content and language integrated learning (CLIL) or the contentbased instruction (CBI) approaches focus on fostering communicative situations in the classroom, in which the students' language acquisition process is unconscious. In this context, there is a clear division of opinions as it may happen in other research contexts. Some view these approaches with illusion and hope (Coyle, Hood, \& Marsh, 2010; Dalton-Puffer, 2007; Lasagabaster \& Sierra, 2009; Marsh \& Langé, 2000), whereas others seem to reject them (Bruton, 2011; Marias, 2015; Paran, 2013). These opposite views suggest that there are some aspects in their implementation that could be improved and new and supportive alternatives would be beneficial in this field.

This article focuses on the use of serious videogames to give support to teaching language through content subjects as it is the case of CLIL and
$\mathrm{CBI}$; and our objective is to review the literature and explain how content and language based subjects can be integrated and gamified in tailored videogames. In this sense, videogames can be a means of useful support to learners since they provide students with further practice while they are engaged in an entertaining atmosphere. Dörnyei \& Ushioda (2013) claimed that students learn better when they are motivated, both intrinsically and extrinsically. Thus, a positive attitude towards their own learning process would be beneficial (Lasagabaster, Cots, \& ManchoBarés, 2013). To this purpose, the use of videogames for educational purposes can be positive for students and the gamification of language and content learning could result in a breakthrough in the field of education.

\section{Materials}

The application of approaches based on the integration of language and content are increasingly present in schools and universities. The most usual approaches in this context are CLIL and CBI, whose 
differences are insignificant and according to some authors near inexistent (Cenoz, 2015). CBI was first originated in the 1960s in some areas in Canada where both French and English are official languages, as well as other aboriginal languages. This approach focuses on teaching content in a foreign language, but none or little attention is paid to the $\mathrm{L} 2$ (Cenoz, 2015). On the other hand, CLIL was developed and spread in Europe in the 1990s and 2000s. This approach also focuses on teaching contents through a foreign language (Coyle et al., 2010); however, the main focus in CLIL may be placed either on the content, the language, or both at the same time (Massler, Stotz, and Queisser, 2014). Both approaches aim at fostering communicative situations in the classroom, in which the students' language acquisition process is unconscious (Marsh, 2008). The main difference between them is the flexibility of CLIL in order to balance its dual-focused nature and strengthen learners' acquisition of language and content when some linguistic flaws are detected. Thus, students in CLIL can be provided with language literacy support when necessary (Coyle, 2008). The purpose of this support is to enhance learners' acquisition of content in non-linguistic subjects.

These approaches help students develop communication skills, and intercultural knowledge, interests and attitudes towards the language and its speakers; and they also aim at enhancing language competence with a special focus on oral communication skills (Coyle et al., 2010; Marsh,2002; Meyer, 2010).CLIL and $\mathrm{CBI}$ also provide students with comprehensible and meaningful input and opportunities to practice the new knowledge in real communicative situations (Marsh, 2002; 2008). According to Coyle (2007), these communicative situations connect communication, content, culture and cognition, creating a suitable scenario for learning foreign languages. As result, this context enriches the use of the language to express real ideas based on the contents exposed in the subject, being the communication authentic, varied, and relevant (Muñoz, 2007). Another key towards success when using these approaches is the way information is introduced to the students, which should be pleasant, avoiding stress and boredom (Krashen, 2011). Vygotsky (1978) stated that learning is pleasant when the student stays in the zone of proximal development. Krashen (1985) also developed this idea by referring to the need to provide students with tasks at a slightly higher level $(i+l)$.

In the practice, teachers can make their lessons pleasant and comprehensible through experiments, involving interaction, reflection, and problem-solving among students (Skehan, 1998). In this context, videogames can be a real possibility to experiment in content and language based subjects, providing students with pleasant and comprehensible input. Moreover, videogames involve a playful atmosphere that entertains and engage students through their learning processes (Galloway, 2004). Thus, videogames can be a suitable tool for content and language learning since they extend the time of exposure to language and content and can provide further opportunities for practice (Roediger \& Karpicke, 2006). In this sense, there have been some previous experiences in which videogames have been used for educational purposes. According to Michael Sutton in an interview (Costea, 2016), there is an emerging and growing market of tailor-made serious videogames addressed to companies and institutions, which require specific training programs. Their main customers are multinational private companies as well as governmental entities such as military, education or health services. These videogames are adapted to be played in computer and consoles and some of them also offer serious videogames to be played with smartphones. Similarly, other academic institutions have also developed some projects; in this sense, some examples of serious games applied to teaching languages have been shown in Tsalapatas et al. (2014), Johnson, Vilhjalmsson \& Samtani (2005), CalvoFerrer (2013). Other experiences are also mentioned in Hainey \& Connolly (2013), such as: Akcaoglu, (2011), Dourda, Bratitsis, Griva \& Papadopoulou (2014), Pivec $\&$ Dziabenko (2004), Vos, van der Miejden \& Denessen (2011). With the support of these previous experiences, the use of videogames for educational purposes seems to be a positive experience for students and it can be integrated in subjects dealing with content and language at the same time (namely CLIL and CBI) as well as with those in which content and language are introduced in isolation, as happens in more traditional methods. Having considered the information provided in this section, this paper focuses on reviewing previous research about how to gamify content and language based subjects in tailored videogames.

\section{Methods}

When talking about gamification, this involves any area that can be treated as a game. In this sense, games or videogames can be used for pedagogical purposes, these being known as serious games. For our purposes, this section focuses on determining the main features to gamify subjects based on the content and language integrated learning approach through the use of videogames. In this sense, the integration of content and language learning has been largely discussed during the last decade in Europe, especially since Marsh (1994) introduced CLIL, a similar approach to CBI as mentioned above. The implementation of CLIL is based on the ' 4 C' framework introduced by Coyle (2005). This framework aims at helping teachers to 
obtain the appropriate design of the CLIL approach; and the ' $4 \mathrm{C}$ ' represent the connection among communication, content, cognition and culture (see Figure 1).

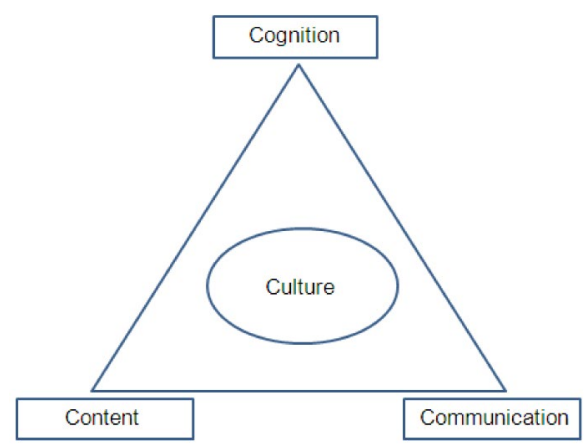

Figure 1. The '4 C' framework for CLIL. Adapted from “CLIL: Planning tools for teachers,"by D. Coyle, 2005.

The first item in this framework is content, which refers to the theme of a particular non-linguistic subject (e.g., math, history, science, music) and it is considered the main basis for learning. Learners need to acquire some particular knowledge and to develop some specific skills based on that theme. On the basis of the target content, the teacher will establish teaching aims and learning outcomes to determine the students' learning progression. The second item is communication and it focuses on the language that is used as the main instrument to communicate and learn the target contents. In this context, the aim of learning is to use the language; and its use to learn. This element is fundamental to transfer the knowledge derived from the content of the subject; thus the language needs to be clear and comprehensible for the students (Krashen, 1982). Coyle et al. (2010) suggest that students need to be competent with different facets of the language; these can refer to the language of learning (to access to concepts related to the topic), for learning (to operate in the classroom), and through learning (to face unplanned curricular and extracurricular situations). The third element that needs to be considered is cognition. Learners must develop thinking skills in order to link concepts, understanding and language by using their own interpretation of content. Cognition needs to be introduced through tasks that promote problem-solving and higher order thinking processes as suggested by Banegas (2013). At this stage, teachers are responsible to determine the thinking skills that learners need to develop. Bloom (1956) originally introduced his taxonomy of thinking skills with a list of the cognition demands ordered from lower to higher order. Anderson \& Krathwohl (2001) updated this with the use of actions rather than processes, which seems to be more applicable with content and language integrated learning approaches (from lower to higher order thinking skills: remembering, understanding, applying, analyzing, evaluating, and creating).

The triangle formed by content, communication and cognition is complimented with culture. In words of Perez-Gracia (2014), cultural awareness is fundamental in the study of a language. Culture is a valuable source of knowledge to interpret citizenship and to create a feeling of understanding and tolerance among individuals from different backgrounds. It is also used to make students aware of the settings where the target language occurs and they then can extract information about their use in the language natural context.

In addition to the connection among the subject content, cognition, communication and culture, its success may also depend on other aspects that can be either internal or external. Some of the problems that may arise can be the lack of time, students' and teachers' motivation, materials or other resources. In this sense, the use of tailored-made videogames could be a possible solution to some of these problems. Videogames could support students with further content as well as repetitive activities and problemsolving tasks within a playful and engaging atmosphere that would motivate students to continue playing and, consequently, studying. In order to achieve this purpose, the '4 C' framework introduced by Coyle (2005) should be extended with the aim of integrating its components in a videogame. It shall also be noticed that there is a wide variety of videogame genres; each of them offer different ways of playing. However, each of these genres should be based on educational purposes; these are known as 'serious videogames'. Serious videogames are defined as 'a mental contest, played with a computer in accordance with specific rules that uses entertainment to further government or corporate training, education, health, public policy, and strategic communication objectives' (Zyda, 2005, p. 26). In addition to this definition, Malone (1981) had previously appointed a series of characteristics found in serious videogames, features also supported by other more recent authors:

- Clear meaningful learning and playing goals for the students (Gee, 2005; Warren, Scott \& Jones, 2008);

- Students' feedback on their progress (Gross, 2009; Van der Kleij, Feskens, \& Eggen, 2015);

- Adapted difficulty to the learners' skills (Alexander, Sear \& Oikonomou, 2013; O’Brien, Edwards, Maxfield, Peronto, Williams \& Lister, 2013);

- (Driskell, 2002; King, Delfabbro, \& Griffiths, 2010);

- A suitable and attractive setting and design including the same features of non-educational videogames (Gallego-Durán \& Llorens-Largo, 2015).

As it can be observed, there are a series of features that are related to teaching both qualitative and quantitative contents but also to entertaining students. 
A videogame cannot be understood as such without the playful factor. This fact is what motivates students to play and consequently to learn (Dondlinger, 2007). In the field of education, fostering motivation among students shall increase their efforts to complete the task and promote their enjoyment during the gaming time (Gros, 2009). However, not all videogames are the same; they can be classified into different categories and these lists usually vary among authors (see Adams, 2013; Nowak, 2011; Rollings \& Adams, 2003). For example, Adams (2013) introduced the following nine categories: action, action-adventure, adventure, massive multiple-player online (MMO), role-playing, simulation, strategy, vehicle simulation, and other miscellaneous genres.

Each of these genres contains noticeable differences in the way of playing; thus depending on the educational purposes and field of knowledge, some genres may be more suitable than others. In this sense, teachers should consider first the teaching and learning purposes and then decide how to play those educational purposes and select the most suitable genre for that purpose (Deterding, Dixon, Khaled, \& Nacke, 2011). Once these decisions have been taken, the design of the videogame can be started; this is also known as gamification. This term is defined as 'a process of enhancing services with motivational affordances in order to invoke gameful experiences and further behavioral outcomes' (Hamari, Koivisto, \& Sarsa, 2014, p. 3025). Similarly, another definition was provided by (Huotari \& Hamari, 2011, p. 2); in this case gamification can be understood as 'a form of service packaging where a core service is enhanced by a rules-based service system that provides feedback and interaction mechanisms to the user with an aim to facilitate and support the users' overall value creation'. In the practice, Robson, Plangger, Kietzmann, McCarthy \& Pitt (2015) suggested a model of gamification that contains three items: mechanics, dynamics and emotions (see Figure 2).

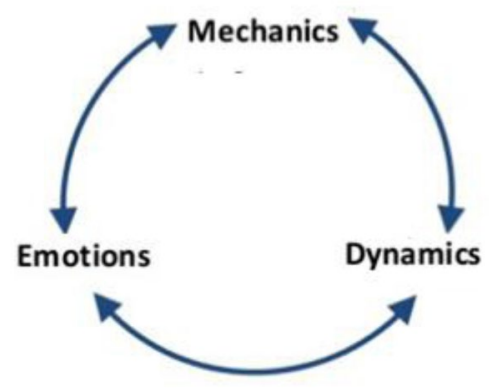

Figure 2. Processing gamification. Adapted from "Is it all a game? Understanding the principles of gamification," by K. Robson, K. Plangger, J. H. Kietzmann, I. McCarthy, \& L. Pitt, 2015.
The first item in this model concerns mechanics: it represents the objectives, rules, setting, context, interactions, and boundaries within the game, driving the action forward and generating engagement (Werbach \& Hunter, 2012). Mechanics can also be divided into three categories. Firstly, setup mechanics determine where it is to be played, what objects are needed for it, and how these are to be distributed. Secondly, rule mechanics shape the goals of the gamified experience. And thirdly, progression mechanics define the type of standings and rewards the player receives along the game such as badges, trophies, or winnings, amongst others. The following item in the model is dynamics; it configures the behavior of the players that participate in the experience. Werbech \& Hunter (2012, p. 93) defined dynamics as, 'the big-picture aspects of the gamified system that you have to consider and manage but which can never directly enter into the game'. In other words, they describe how the rules act in motion, responding to player input and working in concert with other rules (Hunicke, LeBlanc \& Zubek, 2004). Finally, the third item concerns the mental affective states and reactions evoked among individual players. Emotions provide the player with curiosity, competitiveness, frustration, or happiness, among other sensations. As result, players feel themselves emotionally engaged with the game and get involved in the story in the same way books or films do with their audience. Hunicke, LeBlanc \& Zubek (2004, p. 2) introduced the following taxonomy to classify the type of emotions in the field of videogames:

- Sensation: Game as sense-pleasure

- Fantasy: Game as make-believe

- Narrative: Game as drama

- Challenge: Game as obstacle course

- Fellowship: Game as social framework

- Discovery: Game as uncharted territory

- Expression: Game as self-discovery

- Submission: Game as pastime

In addition to the process of gamification introduced by Robson et al. (2015), there are other elements that should be considered when designing serious games. These items provide the necessary educational items in serious videogames. They are engagement, autonomy, mastery and progression and they were introduced by Butler (2016).

- Engagement: Learners better get involved with the games if they provide storytelling, narrative and challenge; consequently they connect with the content. This connection to the content is much stronger when the game is set in a world and is clearly connected to learning. In this sense, students get connected emotionally with the outcome of the game, for example when a player is virtually hurt or their company loses money.

- Autonomy: Players are the protagonist and they 
can take control and explore the virtual world at their own pace taking their own decisions. This favors an increase of the immersion level in their learning processes. Besides, players are also involved in a scene of mystery and suspense since they do not know what will happen next.

- Mastery: Learners gain mastery in both the game and the target content after repeating tasks and mechanizing actions. In turn, students are motivated with a sense of success and enjoyment after completing challenging levels.

- Progression: Learners can witness their progression through gaining rewards or points, achieving ranks, or unlocking levels among others. This motivates students to continue playing and learning until they win or fulfill the purpose of the game.

In sum, this section has introduced the steps for gamification following Butler (2016), Malone (1981), and Robson et al. (2015), among other authors as well as the principles of CLIL and the theories to integrate content and language (Cenoz, 2015; Coyle, 2005; Marsh, 2002). Having considered these ideas, this article focuses on the development of a possible model for the gamification of subjects and their materials in which content and language are integrated.

\section{Discussion and Conclusion}

As stated previously, education is continuously experimenting changes. In this sense, the integration of content and language subjects as well as the incorporation of serious videogames in the educational field have been some of the research tendencies occurring in the 2010s. It is unquestionable that the theories and implementation of any method or approach could be enhanced through innovative perspectives and tools. Thus, this article focuses on the possibility of combining serious videogames and content and language integrated subjects. To this purpose, this paper has introduced the principles of CLIL and CBI (Cenoz, 2015; Marsh, 2002) and the theory of the ' $4 \mathrm{C}$ ' to integrate content and language (Coyle et al., 2010). On the other hand, the characteristics of serious games and videogame genres have also been introduced (Malone, 1981; Adams, 2013). Lastly, gamification and the elements involved in the process of designing educational videogames have been defined (Butler, 2016; Robson et al., 2015; Webach \& Hunter, 2012).

In this sense, considering all the ideas stated previously, this paper introduces a model that aims at integrating content and language learning with serious videogames. In other words, this paper focuses on the possibility to gamify content and language integrated learning (G-CLIL). This proposal could be used as a means of support to the in-class sessions, with the videogame used like a workbook. The use of serious games would increase the time of exposure to the language and content in an entertaining way out of school and it would also provide further opportunities to practice. Our model is divided into four stages and they are presented as a circle covered by three different layers and four additional items that are necessary for designing videogames (see Figure 3). This model must be interpreted from the inner circle to the outer layers.

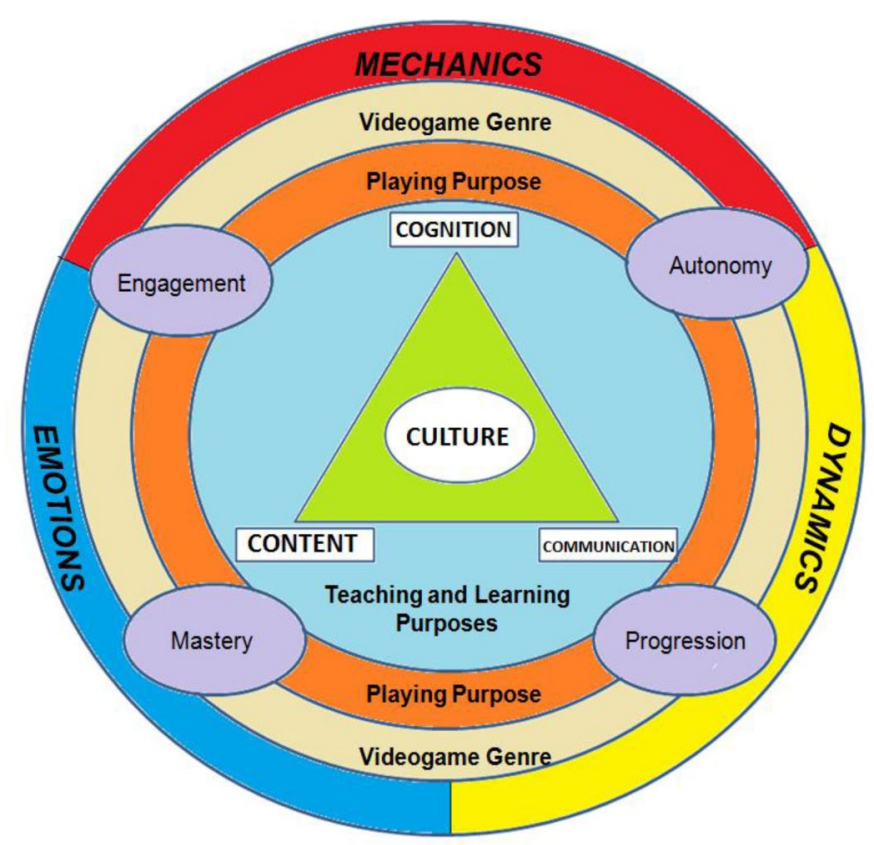

Figure 3. Gamification of content and language integrated learning (G-CLIL).

The first stage towards the gamification of subjects integrating content and language is the analysis of the ' $4 \mathrm{C}$ '. This stage does not differ from the way in which these four items are integrated in CLIL and CBI for developing content and language subjects, as suggested by Coyle et al. (2010). This integration process concerns the determination of the teaching and learning purposes in which educators plan and arrange the type of contents and the language they want to teach. Once this stage has been completed, it is necessary to analyze how the subject (content and language) can be played. It is not the same to play math, history, music, or chemistry. Thus, it shall be necessary to do research on suitable games that can be applied to particular types of contents or language forms. For example, games about the subject of history can be based on adventures as well as in strategy or role games; whereas math can be played with operation or geographical puzzles, and physical education must 
focus on sports or related material.

Once teaching and learning and playing purposes are defined, it is necessary to choose a videogame genre that can be suitable and adaptable to them. To this purpose, the list provided by Adams (2013) can be used; besides any sub-genre derived from the original ones or any combination of these can be also selected. For example, graphic adventures usually combine puzzles and ability. Next, it is necessary to develop the videogame mechanics, dynamics and emotions in order to continue with the gamification process, as suggested by Robson et al. (2015). In this case, this stage involves the development of the videogame itself: scenario, characters, goals, or awards, among others. In addition to these items, the final aim of a videogame is that this will be effective for learning and motivating to continue playing. To fulfill this goal, the four principles introduced by Butler (2016) must be considered for the design of serious videogames with pedagogical purposes. Consequently, autonomy would provide learners with opportunities to learn how to manage and problems individually. In addition, the repetition of tasks would help students to interiorize and master content and language forms. This learning purpose will be fulfilled if the videogame engages the students to continue playing; thus it is necessary to provide storytelling, narrative and challenge that connect with the content and the language that is targeted. This motivation is also related to the learners' progression along the videogame; setting objectives, goals and rewards is fundamental to create addiction.

With the implementation of this model for the Gamification of Content and Language Integrated Learning (G-CLIL), educators may find an interactive, entertaining, and engaging tool to support their students' learning. Through the use of videogames as support to their learning process, the time of exposure will increase, including further repetition of task and activities and it will help to motivate learners in their learning. Lastly, it shall be stated that the main limitation of this research is the actual complexity to design tailored videogames since they require work and collaboration among hybrid groups of researchers including language and content teaching experts as well as videogame ones. To this purpose, universities could offer their support to and coordination among experienced researchers in the field of foreign language and content learning and teaching as well as videogames with the goal of developing serious videogames aimed at supporting teaching materials. At the same time, further research on this topic could lead to determine the benefits of using videogames in content and language integrated learning and to assess its efficiency among learners.

\section{References}

Adams, E. (2013). Fundamentals of game design. San Francisco, CA: New Riders.

Akcaoglu, M. (2011). Using games in classroom: All tutors and no stories make a virtual world a dull game. In M. Koehler \& P. Mishra (Eds.), Proceedings of Society for Information Technology \& Teacher Education International Conference (pp. 64-69). Chesapeake, VA: Association for the Advancement of Computing in Education.

Alexander, J. T., Sear, J., \& Oikonomou, A. (2013). An investigation of the effects of game difficulty on player enjoyment. Entertainment computing, 4(1), 53-62.

Anderson, L., \& Krathwohl, D. (2001). A taxonomy for learning, teaching, and assessing: A revision of bloom's taxonomy of educational objectives. New York, NY: Longman.

Banegas, D. (2013). The integration of content and language as a driving force in the EFL lesson. In E. Ushioda (Ed.), International Perspectives on Motivation: Language Learning and Professional Challenges (pp. 82-97). New York, NY: Palgrave Macmillan.

Bloom, B. S. (1956). Taxonomy of educational objectives: The classification of educational goals. New York, NY: David McKay.

Bruton, A.(2011). Is CLIL so beneficial, or just selective? Re-evaluating some of the research. System, 39(4), 523-532.

Butler, J. (2016). The role of games in digital learning. E-learning network. Retrieved from http: //www. elearningnetwork.org/

Calvo-Ferrer, J. R. (2013). Videojuegos y aprendizaje de segundas lenguas: Análisis del videojuego 'The Conference Interpreter' para la mejora de la competencia terminológica [Video games and learning second languages: Analysis of the videogame 'The Conference Interpreter' for the improvement of the competence terminology]. Alicante, Spain: Universidad de Alicante.

Cenoz,J.(2015). Content-based instruction and content and language integrated learning: The same or different? Language, Culture and Curriculum, 28(1), 8-24.

Costea, A. (2016). Consultant interview: Michael J. Sutton. Performance Magazine. Retrieved from http://www.performancemagazine.org/ consultant-gsa-vrs-michael-sutton/

Coyle, D. (2005). CLIL: Planning tools for teachers. Nottingham, UK: University of Nottingham.

Coyle, D. (2007). Content and language integrated 
learning: Towards a connected research agenda for CLIL pedagogies. International Journal of Bilingual Education and Bilingualism, 10(1), 543-562.

Coyle, D. (2008). CLIL - A pedagogical approach from the European perspective. In Encyclopedia of language and education (pp. 1200-1214). Ney York, NY: Springer.

Coyle, D., Hood, P., \& Marsh, D. (2010). Content and language integrated learning. Stuttgart, Germany: Ernst Klett Sprachen.

Dalton-Puffer, C. (2007). Discourse in content and language integrated learning (CLIL) classrooms. Amsterdam, PA: John Benjamins Publishing.

Deterding, S., Dixon, D., Khaled, R., \& Nacke, L. (2011). From game design elements to gamefulness: Defining gamification. In Proceedings of the 15th international academic MindTrek conference: Envisioning future media environments (pp. 9-15). New York, NY: Association for Computing Machinery Publications.

Dondlinger, M. J. (2007). Educational video game design: A review of the literature. Journal of applied educational technology, 4(1), 21-31.

Dörnyei, Z., \& Ushioda, E. (2013). Teaching and researching: Motivation. New York, NY: Routledge.

Dourda, K., Bratitsis, T., Griva, E., \& Papadopoulou, P. (2014). Content and language integrated learning through an online game in primary school: A case study. The Electronic Journal of e-Learning, 12(3), 243-258.

Gallego-Durán, F., \& Llorens-Largo, F. (2015). ¡Gamificad, insensatos! [Gamify, you mad!]. In Proceedings of the XXI Congress on computing teaching at university (pp. 240-247). Andorra la Vella, Spain: Universitat Oberta la Salle.

Galloway, A. R. (2004). Social realism in gaming. The international journal of computer game research, 4(1). http://gamestudies.org/0401/galloway/

Garris, R., Ahlers, R., \& Driskell, J. E. (2002). Games, motivation, and learning: A research and practice model. Simulation \& Gaming, 33(4), 441-467.

Gee, J. P. (2005). Learning by design: Good video games as learning machines. E-Learning and digital media, 2(1), 5-16.

Gros, B. (2009). Certezas e interrogantes acerca del uso de los videojuegos para el aprendizaje [Certainties and questions about the use of videogames for learning purposes]. Revista Comunicación, 7(1), 251-264.

Hainey, T., \& Connolly, T. (2013, January). Development and evaluation of a generic E-CLIL Web 2.0 games engine. In European Conference on Games Based Learning (pp. 198-212). Porto, Portuguese: Academic Conferences International Limited.

Hamari, J., Koivisto, J., \& Sarsa, H. (2014). Does gamification work? A literature review of empirical studies on gamification. In Proceedings of 47 th Hawaii International Conference on System Sciences (pp. 3025-3034). Hawaii, HO: Institute of Electrical and Electronics Engineers publishing.

Hunicke, R., LeBlanc, M., \& Zubek, R. (2004). MDA: A formal approach to game design and game research. In Proceedings of the AAAI Workshop on Challenges in Game Artificial Intelligence (pp. 1-5). San Jose, CA: Association for the Advancement of Artificial Intelligence.

Huotari, K., \& Hamari, J. (2011). Gamification from the perspective of service marketing. In Proceedings of CHI 2011 Workshop Gamification. Retrieved from http://gamification-research.org/chi2011/papers/

Johnson, W. L., Vilhjalmsson, H., \& Samtani, P. (2005). The tactical language training system. Interactive events. Retrieved from http://citeseerx.ist.psu.edu/ viewdoc/download?doi=10.1.1.296.7826\&rep= rep $1 \&$ type $=$ pdf $\#$ page $=15$

King, D., Delfabbro, P., \& Griffiths, M. (2010). Video game structural characteristics: A new psychological taxonomy. International Journal of Mental Health and Addiction, 8(1), 90-106.

Krashen, S. (1982). Principles and practice in second language acquisition. Pergamon, UK: Oxford.

Krashen, S. D. (1985). The input hypothesis: Issues and implications. New York, NY: Longman.

Krashen, S. (2011). Free voluntary reading. Santa Barbara, CA: Greenwood Publishing.

Lasagabaster, D., Cots, J.M., \& Mancho-Barés, G. (2013). Teachingstaff's views about theinternationalisation of higher education: The case of two bilingual communities in Spain. Multilingua, 32(6), 751-778.

Lasagabaster, D., \& Sierra, J. M. (2009). Immersion and CLIL in English: More differences than similarities. ELT Journal, 64(4), 367-375.

Malone, T. W. (1981). What makes things fun to learn? A study of intrinsically motivating computer games. Pipeline, 6(2), 50-51.

Marias J. (2015) Ni bilingüe ni enseñanza [Neither bilingualnoreducation].Retrievedfrom http://elpais. com/elpais/2015/05/13/eps/1431541076_553813. html

Marsh, D. (1994). Bilingual education and content and language integrated learning. Paris, France: University of Sorbonne.

Marsh, D. (2002). Content and language integrated learning: The European dimension - Actions, trends and foresight potential. Jyväskylä, Finland: University of Jyväskylä.

Marsh, D. (2008). Language awareness and CLIL. In Encyclopedia of language and education (pp. 19861999). New York, NY: Springer.

Marsh, D., \& Langé, G. (2000). Using languages to learn and learning to use languages. Jyväskylä, Finland: University of Jyväskylä. 


\section{RICARDO CASAÑ PITARCH}

Massler, U., Stotz, D., \& Queisser, C. (2014). Assessment instruments for primary CLIL: The conceptualisation and evaluation of test tasks. The Language Learning Journal, 42(2), 137-150.

Meyer, O. (2010). Towards quality CLIL: Successful planning and teaching strategies. Puls, 33(1), 1129.

Muñoz, C. (2007). CLIL: Some thoughts on its psycholinguistic principles. In F. Lorenzo, S. Casal, V. de Alba \& P. Moore (Eds.), Models and practice in CLIL. Volúmen Monográfico (pp. 17-26). Seville, Spain: University Pablo de Olavide.

Novak, J. (2011). Game design essentials: An introduction. Boston, MA: Cengage learning.

O’Brien, J., Edwards, J., Maxfield, N., Peronto, C., Williams, V., \& Lister, J. (2013). Cognitive training and selective attention in the aging brain: An electrophysiological study. Clinical neurophysiology, 124(11), 2198-2208.

Paran, A. (2013). Content and language integrated learning: Panacea or policy borrowing myth? Applied Linguistics Review, 4(2), 317-342.

Pérez Gracia, E. (2014). Multicultural education for language teacher education and CLIL. In Conference proceedings ICT for language learning (pp. 42-45). Limena, Italy: Libreria universitaria.it Edizioni.

Pivec, M., \& Dziabenko, O. (2004). Game-based learning framework for collaborative learning and student e-teamwork. Journal of Universal Computer Science, 10(1), 4-12.

Robson, K., Plangger, K., Kietzmann, J. H., McCarthy, I., \& Pitt, L. (2015). Is it all a game? Understanding the principles of gamification. Business Horizons, 58(4), 411-420.

Roediger, H. L., \& Karpicke, J. D. (2006). Test-enhanced learning taking memory tests improves long-term retention. Psychological Science, 17(3), 249-255.

Rollings, A., \& Adams, E. (2003). Andrew Rollings and Ernest Adams on game design. San Francisco, CA: New Riders.

Skehan, P. (1998). A cognitive approach to language learning. Oxford, UK: Oxford University.

Tsalapatas, H., Heidmann, O., Alimisi, R., Tsalapatas, S., Kourias, S., Sillaots, M., Hourmat, B., Tramonti, M., Oie, S., \& Houstis, E. (2014). Serious game design for vehicular language learning addressing work needs. In A. De Gloria (Ed.), Games and Learning Alliance (pp. 383-389). Cham, Germany: Springer.

van der Kleij, F. M., Feskens, R. C., \& Eggen, T. J. (2015). Effects of feedback in a computer-based learning environment on students' learning outcomes: A meta-analysis. Review of Educational Research, 85(4), 475-511.

Vos, N., van der Miejden, H., \& Denessen, E. (2011). Effects of constructing versus playing an educational game on student motivation and deep learning strategy use. Computers and Education, 56(1), 127-137.

Vygotsky, L. S. (1978). Mind in society: The development of higher psychological processes. Cambridge, MA: Harvard University Press.

Warren, S., Scott, J., \& Jones, G. (2008). Yokoi's theory of lateral innovation: Applications for i-manager's. Journal of Educational Technology, 5(2), 32-43.

Werbach, K., \& Hunter, D. (2012). For the win: How game thinking can revolutionize your business. Philadelphia, PA: Wharton Digital Press.

Zyda, M. (2005). From visual simulation to virtual reality to games. Computer, 38(9), 25-32. 